\title{
Personality traits and virtual reality performance
}

\author{
Rachel Rosenthal · Juliane Schäfer • \\ Henry Hoffmann - Martina Vitz - Daniel Oertli • \\ Dieter Hahnloser
}

Received: 23 January 2012/ Accepted: 30 May 2012/Published online: 30 June 2012

(C) Springer Science+Business Media, LLC 2012

\begin{abstract}
Background Surgeons' personalities have been described as different from those of the general population, but this was based on small descriptive studies limited by the choice of evaluation instrument. Furthermore, although the importance of the human factor in team performance has been recognized, the effect of personality traits on technical performance is unknown. This study aimed to compare surgical residents' personality traits with those of the general population and to evaluate whether an association exists between their personality traits and technical performance using a virtual reality (VR) laparoscopy simulator.

Methods In this study, 95 participants (54 residents with basic, 29 with intermediate laparoscopic experience, and 12 students) underwent personality assessment using the NEO-Five Factor Inventory and performed five VR tasks of the Lap Mentor ${ }^{\mathrm{TM}}$ basic tasks module. The residents' personality traits were compared with those of the general population, and the association between VR performance and personality traits was investigated.
\end{abstract}

R. Rosenthal $(\square) \cdot$ J. Schäfer · H. Hoffmann · D. Oertli Department of Visceral Surgery, Basel University Hospital, Spitalstrasse 26, 4031 Basel, Switzerland

e-mail: rrosenthal@uhbs.ch

J. Schäfer

Basel Institute for Clinical Epidemiology and Biostatistics,

Basel University Hospital, Basel, Switzerland

M. Vitz

Laparoscopic Training Center, Zurich, Switzerland

D. Hahnloser

Department of Visceral Surgery, Lausanne University Hospital, Lausanne, Switzerland
Results Surgical residents showed personality traits different from those of the general population, demonstrating lower neuroticism, higher extraversion and conscientiousness, and male residents showed greater openness. In the multivariable analysis, adjusted for gender and surgical experience, none of the personality traits was found to be an independent predictor of technical performance.

Conclusions Surgical residents present distinct personality traits that differ from those of the general population. These traits were not found to be associated with technical performance in a virtual environment. The traits may, however, play an important role in team performance, which in turn is highly relevant for optimal surgical performance.

Keywords Performance $\cdot$ Personality $\cdot$ Surgery · Virtual reality

A surgeon must be competent in terms of technical and nontechnical skills. Technical skills can be trained and objectively measured with virtual reality (VR) simulators [1-5]. Nontechnical skills have gained increasing interest. The impact of teamwork, leadership, communication, situation awareness, and decision making on error minimization has been recognized, and assessment tools for nontechnical skills have been described [6-8].

Personality traits may have an impact on behavior in the operating room [9]. Personality types such as extraversion versus introversion, sensing versus intuition, thinking versus feeling, and judging versus perceiving are assumed to be crucial for team success, which depends on leadership, communication, cohesion, and personality type heterogeneity [10]. 
Surgeons and surgical residents have been described as presenting a distinct personality. Half a century ago, US medical students described surgeons as domineering, arrogant, aggressive, full of energy, and mainly concerned with their own prestige [11]. Similarly, nonsurgeon medi$\mathrm{cal} /$ paramedical individuals have used terms with a negative association to describe surgeons, referring to them as "MDeities" [9].

In a study involving 110 physicians of different specialities, surgeons were the most homogeneous group, with similar profiles in terms of interpersonal style, career/lifestyle, personal/motivational traits, and temperament levels [12]. In another study, 24 male and 15 female surgical residents were assessed with the revised NEO Personality Inventory and found to be higher in extraversion, openness, and conscientiousness; similar in agreeableness and male residents were found to be lower in neuroticism [13]. This study, however, was limited by the small number of participants. To our knowledge, the association of personality traits with the technical surgical performance of individual surgeons has not been assessed to date.

The current study aims to compare the personality traits of surgical residents with those of the general population and to evaluate whether an association exists between their personality traits and technical performance using a VR laparoscopy simulator.

\section{Materials and methods}

\section{Subjects}

Medical students and surgical residents with basic and intermediate surgical experience were recruited at the 29th International Gastrointestinal Surgery Workshop held 26 February to 4 March 2011 at Davos, Switzerland. The study was approved by the local ethical committee on 19 May 2010. All the study participants signed an informed consent. Because the study did not prospectively assign human subjects to medical interventions, it was not registered.

Baseline characteristics questionnaire

A questionnaire was completed for general information on age, gender, handedness, and experience in video games, with simulators, and in surgery.

To include surgical experience as a potential confounder in the analyses, the participants were divided into the following three groups: students, residents with basic experience (0-5 laparoscopic cholecystectomies performed), and intermediate experience ( $\geq 6$ laparoscopic cholecystectomies performed).
NEO-Five Factor Inventory (NEO-FFI) for assessing personality

The NEO-FFI according to Costa and McCrae was conducted as outlined in the test manual [14]. In brief, the NEO-FFI is a self-administered inventory of healthy personality traits. A total of 60 statements representing the five personality traits (12 statements per trait) according to the five-factor theory are provided. The five factors are neuroticism, extraversion, openness, agreeableness, and conscientiousness. The testee answers whether he or she agrees on a 5-point scale (strongly agree, agree, neutral, disagree, or strongly disagree) yielding $0-4$ points per statement and a score of $0-48$ per personality trait.

For comparison with the general population, reference values were retrieved from the test manual referring to a population-representative quota sample of 448 women and 423 men [14].

\section{Simulator tasks}

The following tasks were used referring to the Lap Mentor $^{\mathrm{TM}}$ basic tasks module (Simbionix USA Corp., Cleveland, OH 44106, USA): basic tasks 1 (camera manipulation), 3 (hand-eye coordination), 6 (two-handed maneuvers), and 7 (cutting) and procedural task 2 (clipping and cutting of the cystic artery and duct). The tasks were performed twice, and the mean of the two trials was used for subsequent analysis.

The outcome parameters were grouped within three dimensions: (1) time in minutes (evaluated for all 5 tasks), (2) path length of the camera navigation (task 1), and right/ left-hand instrument (all 4 remaining tasks) in centimetres, corresponding to the economy of movement (the lower the distance, the higher the economy of movement), and (3) accuracy in percentage (for maintaining the horizon in task 1 , touching the targets in task 3 , collecting the balls in task 6 , and retracting the object in task 7, the latter was transformed into 100-accuracy (\%) to obtain the same direction (positive vs negative) for all three dimensions).

\section{Statistical analyses}

To compare the personality traits of surgical residents with those of the general population, we calculated the empirical cumulative distribution function (CDF) of the female and male surgical residents and compared it with the empirical CDF of a reference sample consisting of 448 woman and 423 men [14].

To combine measurements of different outcome parameters with a total performance score, we calculated the average of all measurements. Note that component variables were standardized to zero mean and unit variance 
before that to evaluate them on comparable scales. Additionally, we calculated averages grouped within the three dimensions (time, path length, and 100-accuracy) and the five tasks, respectively.

We used multiple linear regression to investigate associations between the total performance score and the five personality traits, adjusting for gender and surgical experience as potential confounders. Modeling assumptions of linearity and constant variance were checked with plots of the residuals against each personality trait and the residuals against the fitted values (Tukey-Anscombe plot), respectively. The normality assumption was checked with a normal probability plot of the residuals.

To check for influential observations, we calculated Cook's distance and refitted our model by leaving out observations (one at a time) that stood out from the others. In multivariate regression, we finally extended the aforementioned model to the following outcome variables: the average of the standardized performance measurements grouped within the three dimensions and the five tasks, respectively.

All data were handled anonymously. The simulator export automatically generated an Excel spreadsheet with a unique participant identifier equal to the questionnaire identifier and all the performance parameters. For our analyses, we used $\mathrm{R}$ version 2.13.1 (R Foundation for Statistical Computing, Vienna, Austria) [15].

\section{Results}

\section{General characteristics}

The study enrolled 95 participants: 45 women $(47 \%)$ and 50 men $(53 \%)$ with a median age of 31 years (interquartile range [IQR] 28,34), corresponding to $98 \%$ of the eligible participants. The participants consisted of 12 medical students (13\%), 54 residents with basic surgical experience $(57 \%)$, and 29 residents (31\%) with intermediate surgical experience. Table 1 provides an overview of the participants' characteristics.

Comparison of surgical residents' personality traits with those of the general population

Comparison of the 83 residents' ( 38 women and 45 men) personality traits with the gender-specific reference values of the general population are shown in Fig. 1A-E (women) and Fig. 2A-E (men). Compared with the general population, both the female and male residents showed less neuroticism, more extraversion and conscientiousness, and similar agreeableness. The women presented similar and the men slightly greater openness.
Table 1 Participants' characteristics

\begin{tabular}{|c|c|c|}
\hline Characteristic & Measure or category & $\begin{array}{l}\text { All } \\
\text { participants } \\
(n=95)\end{array}$ \\
\hline Gender & Female, $n(\%)$ & $45(47)$ \\
\hline Age (years) & Median (IQR) & $31(28-34)$ \\
\hline \multirow[t]{3}{*}{ Handedness } & Right, $n(\%)$ & $86(91)$ \\
\hline & Left, $n(\%)$ & $8(8)$ \\
\hline & Both, $n(\%)$ & $1(1)$ \\
\hline Experience in video games & Yes, $n(\%)$ & $50(53)$ \\
\hline \multirow[t]{3}{*}{ Surgical experience } & Student, $n(\%)$ & $12(13)$ \\
\hline & $\begin{array}{l}\text { Basic experience, } \\
n(\%)\end{array}$ & $54(57)$ \\
\hline & $\begin{array}{l}\text { Intermediate } \\
\quad \text { experience, } n(\%)\end{array}$ & $29(31)$ \\
\hline \multirow[t]{3}{*}{ Position at the hospital } & Student, $n(\%)$ & $12(13)$ \\
\hline & Resident, $n(\%)$ & $80(84)$ \\
\hline & $\begin{array}{l}\text { Board certified, } \\
n(\%)\end{array}$ & $3(3)$ \\
\hline \multirow{5}{*}{$\begin{array}{l}\text { No. of previous laparoscopic } \\
\text { cholecystectomies }\end{array}$} & $0, n(\%)$ & $37(39)$ \\
\hline & $1-5, n(\%)$ & $29(31)$ \\
\hline & $6-20, n(\%)$ & $16(17)$ \\
\hline & $21-100, n(\%)$ & $12(13)$ \\
\hline & $>100, n(\%)$ & $1(1)$ \\
\hline Experience with simulators ${ }^{\mathrm{a}}$ & Yes, $n(\%)$ & $33(35)$ \\
\hline Postgraduate year & Median (IQR) & $2(1-4)$ \\
\hline Neuroticism & Median (IQR) & $16(13-20)$ \\
\hline Extraversion & Median (IQR) & $31(28-35)$ \\
\hline Openness & Median (IQR) & $32(27-36)$ \\
\hline Agreeableness & Median (IQR) & $32(28-36)$ \\
\hline Conscientiousness & Median (IQR) & $37(34-41)$ \\
\hline
\end{tabular}

$I Q R$ interquartile range

a Available in 94 participants

\section{VR performance}

Figure 3A-C depicts the distribution of the different outcome parameters on the VR simulator for all the study participants grouped within the three dimensions: time (min), path length $(\mathrm{cm})$, and 100-accuracy $(\%)$.

Association between personality traits and VR performance

In the multivariable analysis, adjusted for gender and surgical experience, none of the five personality traits was found to be an independent predictor of technical performance on the VR simulator (total performance score) (Table 2). Graphical examination of the residuals did not indicate that the modeling assumptions were violated. A sensitivity analysis without three participants who had 
Neuroticism

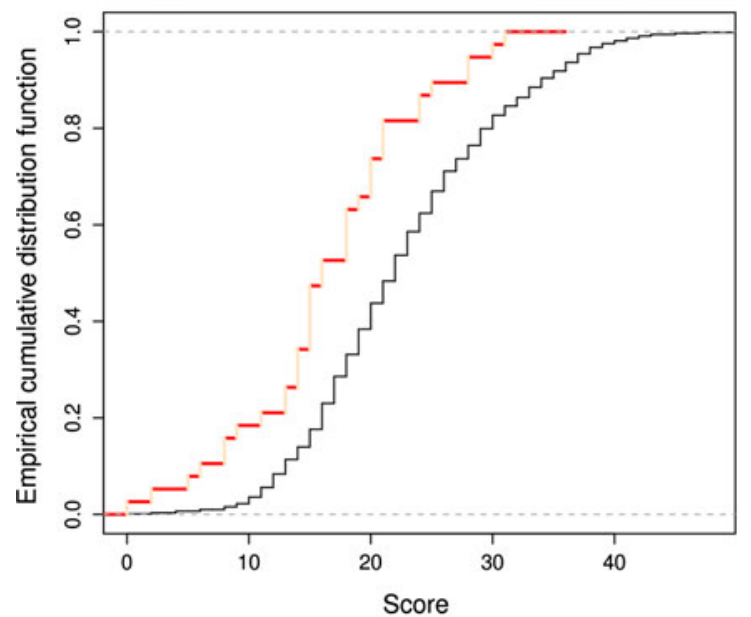

Openness

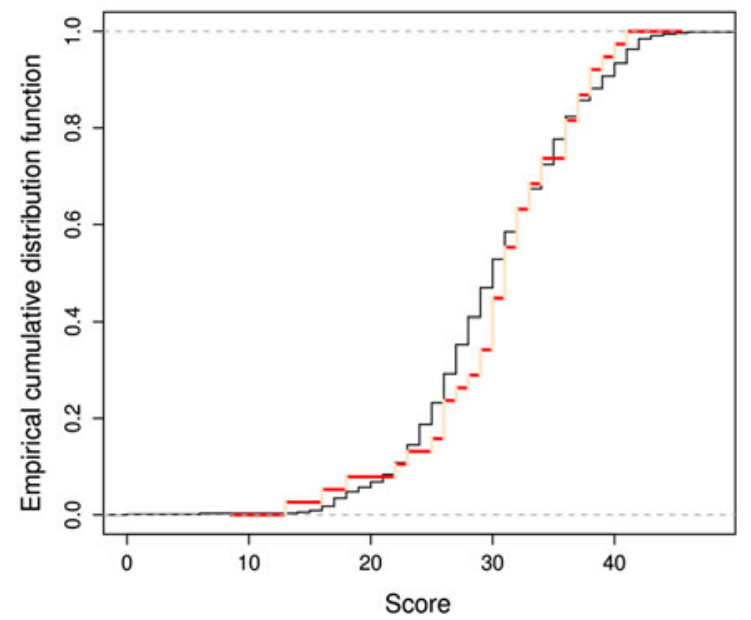

Conscientiousness

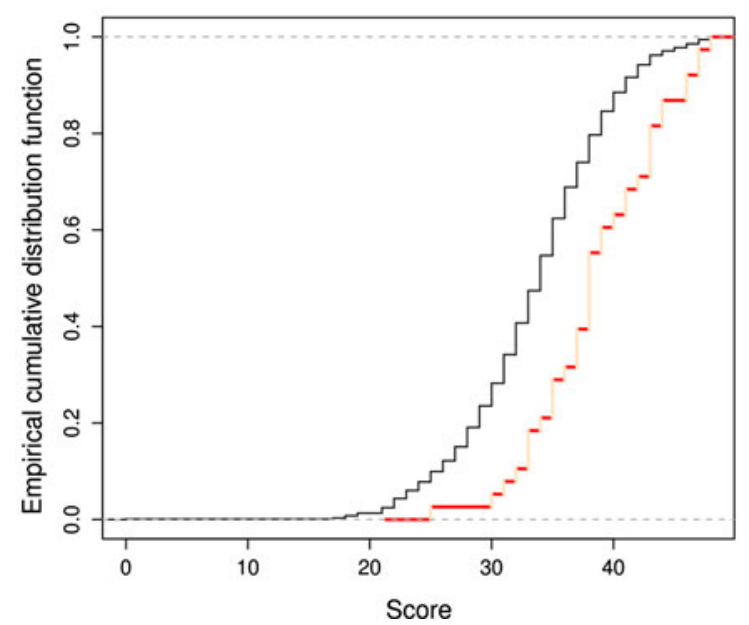

Fig. 1 Empirical cumulative distribution function of the five personality traits of women. In black: female general population (reference values) and in red and grey, respectively (online and printed

\section{Extraversion}

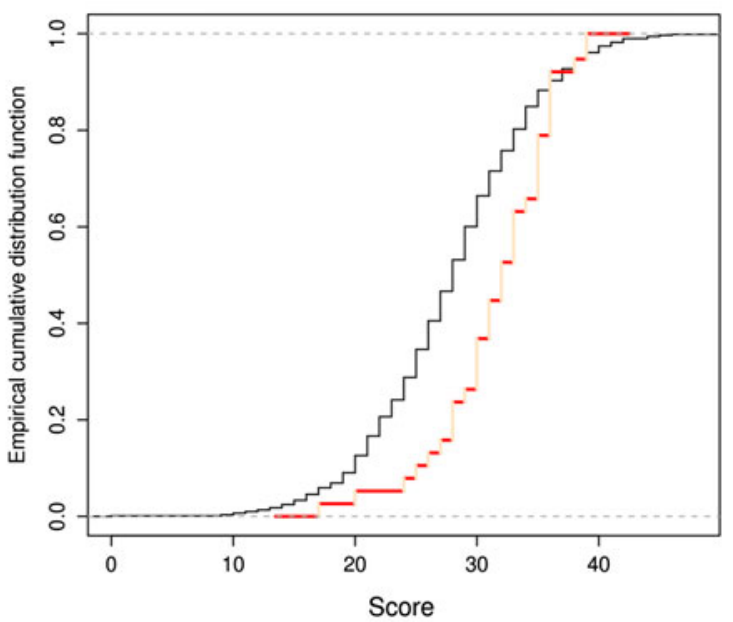

Agreeableness

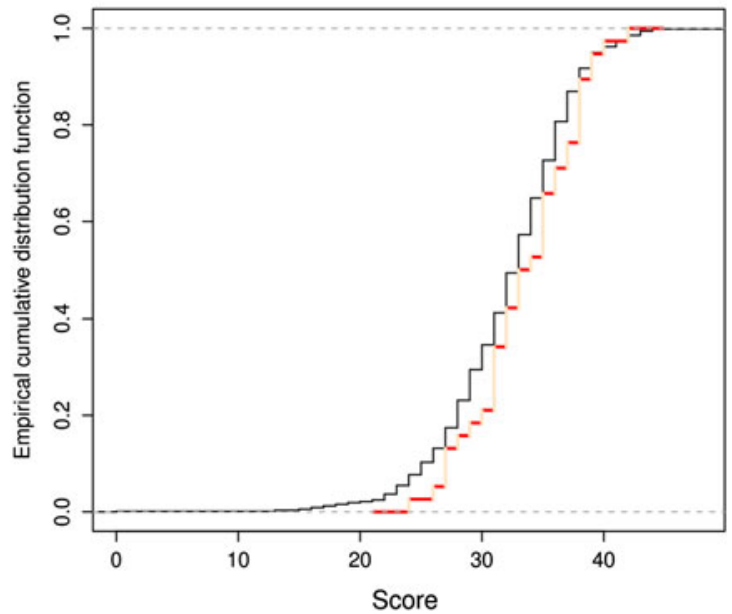

version, respectively): female surgical residents. A Neuroticism. B Extraversion. C Openness. D Agreeableness. E Conscientiousness 

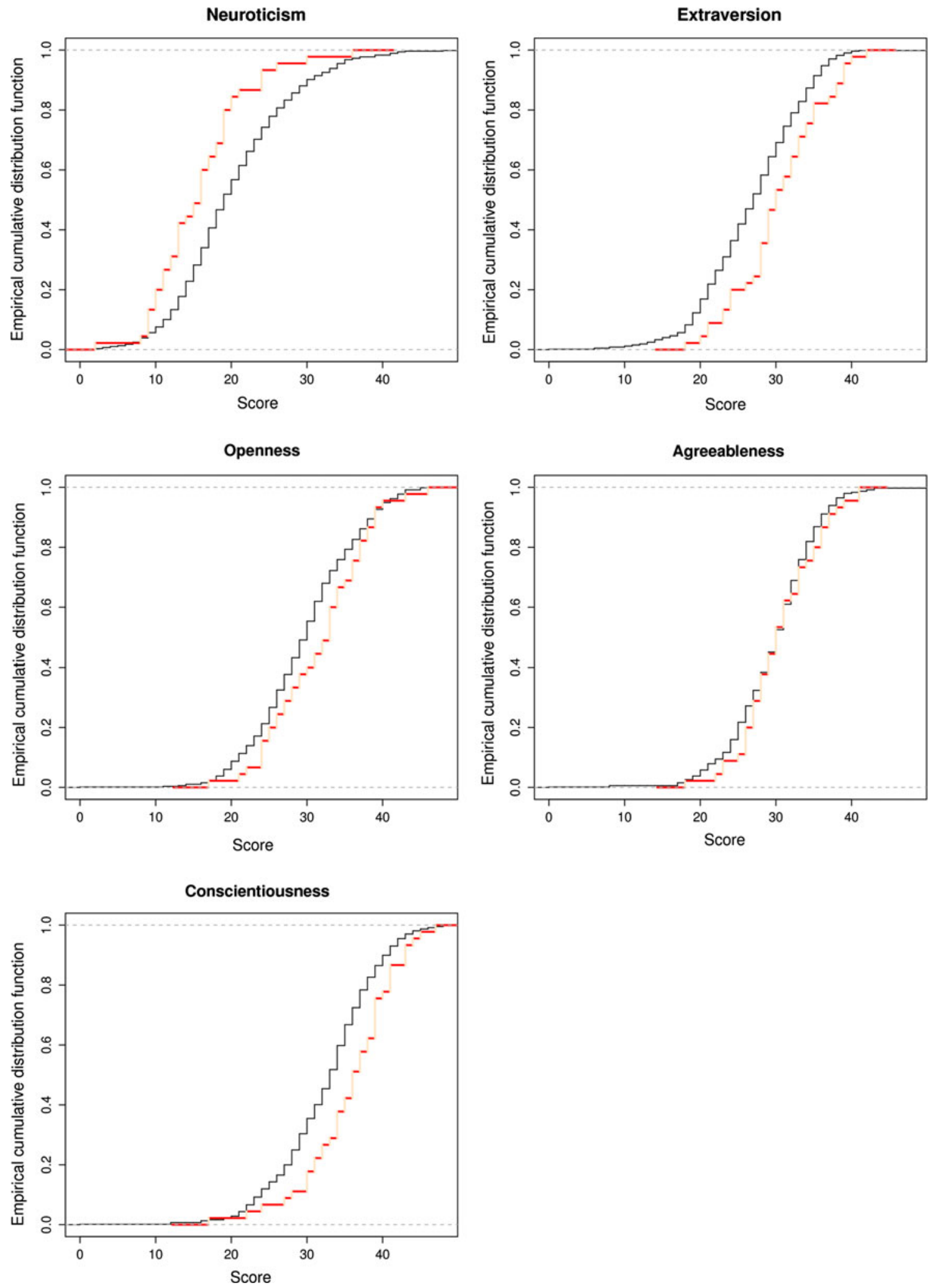

Fig. 2 Empirical cumulative distribution function of the five personality traits of men. In black: male general population (reference values) and in red and grey, respectively (online and printed version,

respectively): male surgical residents. A Neuroticism. B Extraversion. C Openness. D Agreeableness. E Conscientiousness 

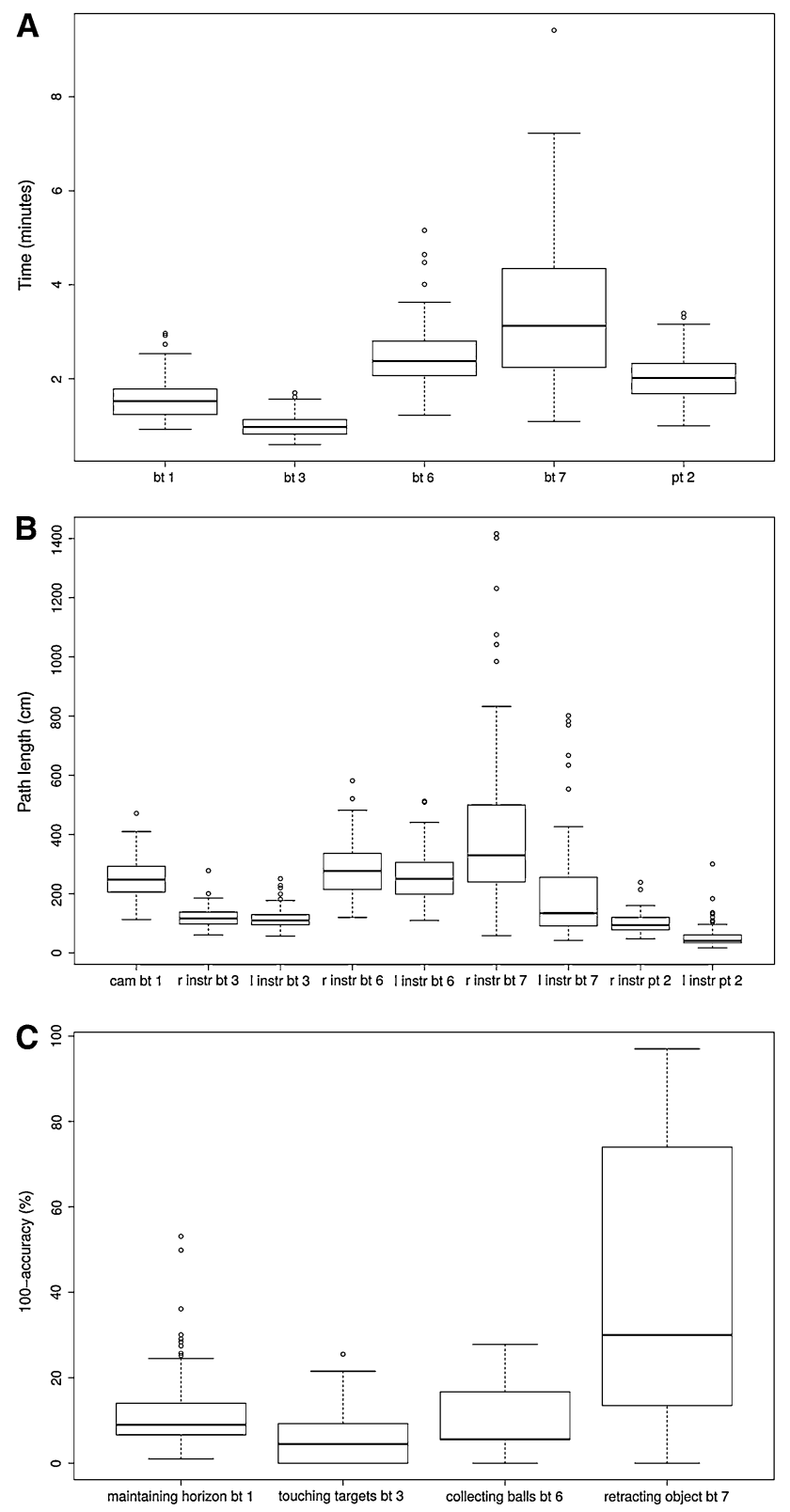

Fig. 3 Box plots showing the distribution of technical performance on the virtual reality simulator grouped in the three dimensions. A Time (min). B Path length (cm). C 100-accuracy (\%). bt basic task, pt procedural task, cam camera navigation, $r / l$ instr right/left instrument

unusually large values for Cook's distance yielded results comparable with those from our primary analysis. When the students $(n=12)$ were excluded from the analysis data set, the results were comparable with those from the primary analysis (Table 2). Neither the grouping of simulator performance within the five tasks nor its grouping within the three dimensions indicated that any personality trait was an independent predictor of technical performance (data not shown).

\section{Discussion}

The results of this study suggest that surgical residents have personality traits different from those of the general population, with less neuroticism, more extraversion and conscientiousness, and in male residents greater openness and that personality traits are not independent predictors of technical performance on a VR simulator.

Previous studies have suggested that surgeons form a distinct and homogeneous population [9, 12]. In an assessment using the revised NEO Personality Inventory, 29 surgical residents showed more extraversion, greater openness and conscientiousness, and less neuroticism among the men and similar agreeableness compared with the general population [13]. The results of our study involving a larger number of participants are in accordance with these findings.

In comparison, US air force pilots show higher levels of extraversion and lower levels of agreeableness than the general population [16].

Surgeons have been compared with medical doctors in other medical specialties. In a survey involving 1,000 surgeons and 1,000 physicians with a $36.5 \%$ response rate, the surgeons were significantly less neurotic and more extraverted than the physicians [17].

A significant stereotype of the personality traits seems to exist. In a survey of the nursing staff at a public tertiary referral hospital involving 543 nurses (62\% response rate), the surgeons were perceived as differing from the physicians in most personality traits such as being less inhibited and more aggressive, with the physicians perceived as more balanced and more socially oriented [18]. In contrast, in a self-assessment of 253 out of 284 surgeons and physicians at the respective hospital ( $89 \%$ response rate), the surgeons differed significantly in only 3 of 12 traits, showing only greater achievement orientation, aggressiveness, and extraversion.

Personality traits may influence surgical program directors to select candidates for a surgical career. In turn, surgical training programs may attract candidates with specific traits. Additionally, surgical training may be a factor in the development of the surgical personality, especially in the case of strong role models [9, 13].

Interestingly, a new type of trainee seems to be attracted recently [19]. In the past, surgeons trained under the apprenticeship model presented mainly with an extraverted-sensing-thinking-and-judging (ESTJ) personality type favoring spoken over written communication and learning through action, interaction, and discussion. The most commonly found modern-generation surgeon, however, is an introverted-sensing-thinking-and-judging (ISTJ) personality type characterized by introversion and favoring written over spoken communication, internal reflection, 
Table 2 Multiple linear regression relating technical performance on the virtual reality simulator (total performance score) with the five personality traits adjusted for gender and surgical experience

\begin{tabular}{|c|c|c|c|c|}
\hline Analysis data set & Personality trait & Coefficient & $95 \% \mathrm{CI}$ & $P$ value \\
\hline \multirow[t]{5}{*}{ All study participants $(n=95)$} & Neuroticism $^{\mathrm{a}}$ & -0.020 & $-0.104,0.065$ & 0.649 \\
\hline & Extraversion $^{a}$ & 0.000 & $-0.109,0.109$ & 0.999 \\
\hline & Openness $^{\mathrm{a}}$ & 0.014 & $-0.074,0.102$ & 0.751 \\
\hline & Agreeableness $^{\mathrm{a}}$ & 0.002 & $-0.112,0.116$ & 0.972 \\
\hline & Conscientiousness $^{\mathrm{a}}$ & -0.011 & $-0.109,0.087$ & 0.826 \\
\hline \multirow[t]{5}{*}{ Surgical residents $(n=83)$} & Neuroticism $^{\mathrm{a}}$ & -0.014 & $-0.104,0.077$ & 0.766 \\
\hline & Extraversion $^{\mathrm{a}}$ & -0.010 & $-0.125,0.105$ & 0.867 \\
\hline & Openness $^{\mathrm{a}}$ & 0.025 & $-0.071,0.120$ & 0.610 \\
\hline & Agreeableness $^{\mathrm{a}}$ & 0.033 & $-0.090,0.156$ & 0.596 \\
\hline & Conscientiousness $^{\mathrm{a}}$ & 0.002 & $-0.106,0.109$ & 0.975 \\
\hline
\end{tabular}

CI confidence interval

a Per 5 points increase

and independent thinking [19]. This change is reflected in the different communication styles between older workers ("pre-boomer" and "boomer" generation), who like to discuss ideas and issues, and younger workers ("cusper," "buster," and "netster" generation), who present a more blunt communication style and are less keen to hear others' opinions or to participate in meetings [20].

Most studies investigating the surgical personality have been mainly descriptive. Recently, however, in a study of 63 surgical residents and 27 attending/teaching surgeons, the results of a personality assessment were compared with a ranking based on a variety of criteria. The criteria involved clinical work, teaching, and research for the attending/teaching surgeons and an evaluation concerning overall performance, academic assessment, examinations, and multisource assessments of residents [21]. The highperforming residents had significantly higher scores than the low-performing residents for the indicators "versatile" and "rigorous." The profile of the attending/teaching surgeons was similar to that of the high-performing residents and differed from that of the low-performing residents.

To our knowledge, the association of personality traits with technical surgical performance has not been assessed to date. We chose additionally to address this question within a standardized VR environment. There, we found no evidence that any personality trait was an independent predictor of performance.

These findings are expected and may be seen as analogous to the findings of a study performed within an anesthesiology training program evaluating 25 anesthesiology residents [22]. In that study, high-competency residents showed significantly greater cooperation, self-efficacy, and adventurousness and less neuroticism, anxiety, anger, and vulnerability than low-competency residents, but the two groups did not differ in terms of fine motor dexterity, executive functioning, processing speed, or attention.
To perform a laparoscopic task successfully, visual information-processing speed, visual-spatial short-term memory, coordination, fine-manipulation dexterity, and spatial skills are described to be important [23-25]. Personality traits probably cannot be expected to have a direct impact on technical performance in this setting, but it must be considered that involving a greater number of participants with heterogeneous personalities (e.g., participants not involved in surgery) would yield an association. For instance, a person with a high degree of conscientiousness could be expected to take his or her time to perform a task very diligently, resulting in greater accuracy and time to complete the task than shown by a person with a low degree of conscientiousness.

In the operating room representing a complex environment, nontechnical skills such as anticipation, resource management, communication style, conflict resolution, decision making, and leadership are important for safe surgical practice [7]. Communication breakdown is one of the most frequently reported factors (43\%) contributing to surgical errors [6]. In anesthetic incidents, human error was found to be involved in $80 \%$ of cases [26].

Applying the systems approach to address errors implicates not only the single individual, but also the entire team, the task, and the working environment [27]. In contrast to the role of personality traits in technical performance, these are expected to play a significant role concerning nontechnical skills, team performance, and finally, safe surgery.

For further research, we plan to investigate, at a previously described interdisciplinary simulation center [28], the relationship between personality traits and team performance in routine situations and critical incidents. Behavior will be rated based on the recently re-evaluated [29] Nontechnical skills for surgeons (NOTSS) system [8], with a focus on situation awareness, decision making, task management, leadership, communication, and teamwork. 
Our study had some limitations. First, we recruited participants attending a training course, so a certain selection bias may not be excluded. The participation rate of the eligible testees, however, was very high.

Second, we focused on a personality test, which may have been limited because it was self-administered. This limitation has been discussed especially in the setting of personnel selection [30], which is different from the use in our study. Moreover, the test is a validated test used extensively. It was developed as a straightforward tool to provide estimates, not definitive measurements of personality traits [31]. The results may be seen as exploratory and helpful for the design of future research.

Third, the VR environment is different from the operating room environment. However, we chose this setting so we would not need to rely on scoring by assessors, but would be able to use the objective simulator metrics for evaluation within a standardized setting.

Fourth, the number of participants included in this study was limited, and they presented a quite homogeneous group. Despite control for potential confounders, this may have contributed to the fact that personality traits were not found to be associated with VR performance.

Finally, the participants performed each task only twice. We therefore were presumably collecting data during the learning curve at the simulator. We preferred, however, to include several different tasks rather than have more repetitions per task.

In conclusion, whereas surgical residents present distinct personality traits that differ from those of the general population, as expected, the study found no evidence that these traits are predictors of technical performance in a virtual environment. The personality traits, however, may play an important role in team performance, which in turn is highly relevant for an optimal surgical outcome.

\begin{abstract}
Acknowledgments The authors' acknowledge all the study participants, the board of directors, and the faculty at the 29th International Gastrointestinal Surgery Workshop held at Davos 2011 for supporting our study. This study was supported by Swiss National Science Foundation grant 3200B0-120722/1. The Basel Institute for Clinical Epidemiology and Biostatistics is supported by grants from Santésuisse and from the Gottfried and Julia Bangerter-Rhyner Foundation. The funding source had no role in the design or performance of the study; the collection, management, analysis, or interpretation of the data; or the preparation, review, or approval of the manuscript.
\end{abstract}

Disclosures Rachel Rosenthal, Juliane Schäfer, Henry Hoffmann, Martina Vitz, Daniel Oertli, and Dieter Hahnloser have no conflicts of interest or financial ties to disclose.

\section{References}

1. Seymour NE, Gallagher AG, Roman SA, O’Brien MK, Bansal VK, Andersen DK, Satava RM (2002) Virtual reality training improves operating room performance. Ann Surg 236:458-464
2. Grantcharov TP, Kristiansen VB, Bendix J, Bardram L, Rosenberg J, Funch-Jensen P (2004) Randomized clinical trial of virtual reality simulation for laparoscopic skills training. Br J Surg 91(146-150):23

3. Andreatta PB, Woodrum DT, Birkmeyer JD, Yellamanchilli RK, Doherty GM, Gauger PG, Minter RM (2006) Laparoscopic skills are improved with LapMentor ${ }^{\mathrm{TM}}$ training: results of a randomized, double-blinded study. Ann Surg 243:854-863

4. McDougall EM, Corica FA, Boker JR, Sala LG, Stoliar G, Borin JF, Chu FT, Clayman RV (2006) Construct validity testing of a laparoscopic surgical simulator. J Am Coll Surg 202:779-787

5. Yamaguchi S, Konishi K, Yasunaga T, Yoshida D, Kinjo N, Kobayashi K, Ieiri S, Okazaki K, Nakashima H, Tanoue K, Maehara Y, Hashizume M (2007) Construct validity for eye-hand coordination skill on a virtual reality laparoscopic surgical simulator. Surg Endosc 21:2253-2257

6. Gawande AA, Zinner MJ, Studdert DM, Brennan TA (2003) Analysis of errors reported by surgeons at three teaching hospitals. Surgery 133:614-621

7. Yule S, Flin R, Paterson-Brown S, Maran N (2006) Nontechnical skills for surgeons in the operating room: a review of the literature. Surgery 139:140-149

8. Yule S, Flin R, Maran N, Rowley D, Youngson G, PatersonBrown S (2008) Surgeons' nontechnical skills in the operating room: reliability testing of the NOTSS behavior rating system. World J Surg 32:548-556

9. Thomas JH (1997) The surgical personality: fact or fiction. Am J Surg 174:573-577

10. Bradley JH, Hebert FJ (1997) The effect of personality type on team performance. J Manag Dev 16:337-353

11. Bruhn JG, Parsons OA (1964) Medical student attitudes toward four medical specialties. J Med Educ 39:40-49

12. Schwartz RW, Barclay JR, Harrell PL, Murphy AE, Jarecky RK, Donnelly MB (1994) Defining the surgical personality: a preliminary study. Surgery 115:62-68

13. McGreevy J, Wiebe D (2002) A preliminary measurement of the surgical personality. Am J Surg 184:121-125

14. Borkenau P, Ostendorf F (2008) NEO-fünf-faktoren-inventar nach costa und mccrae (manual). Hogrefe, Göttingen

15. R Development Core Team (2011) R: a language and environment for statistical computing. R Foundation for Statistical Computing, Vienna. ISBN 3-900051-07-0. http://www.Rproject.org. Accessed 21 June 2011

16. Callister JD, King RE, Retzlaff PD, Marsh RW (1999) Revised NEO personality inventory profiles of male and female US Air Force pilots. Mil Med 164:885-890

17. McCulloch P, Kaul A, Wagstaff GF, Wheatcroft J (2005) Tolerance of uncertainty, extroversion, neuroticism, and attitudes to randomized controlled trials among surgeons and physicians. Br J Surg 92:1293-1297

18. Warschkow R, Steffen T, Spillmann M, Kolb W, Lange J, Tarantino I (2010) A comparative cross-sectional study of personality traits in internists and surgeons. Surgery 148:901-907

19. Swanson JA, Antonoff MB, D'Cunha J, Maddaus MA (2010) Personality profiling of the modern surgical trainee: insights into generation X. J Surg Educ 67:417-420

20. Kennedy MM (2002) Managing change: understanding the demographics of the evolving workforce. Proc Annu Conv AAEP 48:467-470

21. Foster KN, Neidert GP, Brubaker-Rimmer R, Artalejo D, Caruso DM (2010) A psychological profile of surgeons and surgical residents. J Surg Educ 67:359-470

22. Merlo LJ, Matveevskii AS (2009) Personality testing may improve resident selection in anesthesiology programs. Med Teach 31:e551-e554

23. Cadeddu JA, Kondraske GV (2007) Human performance testing and simulators. J Endourol 21:300-304 
24. Wanzel KR, Hamstra SJ, Caminiti MF, Anastakis DJ, Grober ED, Reznick RK (2003) Visual-spatial ability correlates with efficiency of hand motion and successful surgical performance. Surgery 134:750-757

25. Rosenthal R, Hamel C, Oertli D, Demartines N, Gantert WA (2010) Performance on a virtual reality angled laparoscope task correlates with spatial ability of trainees. Indian J Surg 72:327-330

26. Fletcher GC, McGeorge P, Flin RH, Glavin RJ, Maran NJ (2002) The role of nontechnical skills in anaesthesia: a review of current literature. Br J Anaesth 88:418-429

27. Reason J (2000) Human error: models and management. BMJ 320:768-770

28. Rosenthal R, Gisin S, Gantert W, Ummenhofer W, Zobrist R, Oertli D, Scheidegger D (2006) ACMS—advanced complication management simulation. Swiss Knife 1:15-16
29. Crossley J, Marriott J, Purdie H, Beard JD (2011) Prospective observational study to evaluate NOTSS (nontechnical skills for surgeons) for assessing trainees' nontechnical performance in the operating theatre. Br J Surg 98:1010-1020

30. Morgeson FP, Campion MA, Dipboye RL, Hollenbeck JR, Murphy K, Schmitt N (2007) Are we getting fooled again? Coming to terms with limitations in the use of personality tests for personnel selection. Pers Psychol 60:1029-1049

31. McCrae RR, Costa PT Jr (2004) A contemplated revision of the NEO five-factor inventory personality and individual differences 36:587-596 